University for Business and Technology in Kosovo

UBT Knowledge Center

UBT International Conference

2014 UBT International Conference

Nov 7th, 2:15 PM - 2:30 PM

\title{
A Synthesis of Architectural Form for Three Different Structural Systems
}

Hektor Cullufi

Polytechnic University of Tirana

Altin Bidaj

Polytechnic University of Tirana

Ervin Paci

Polytechnic University of Tirana

Irakli Premti

Polytechnic University of Tirana

Drilona Disha

Polytechnic University of Tirana

Follow this and additional works at: https://knowledgecenter.ubt-uni.net/conference

Part of the Architecture Commons

\section{Recommended Citation}

Cullufi, Hektor; Bidaj, Altin; Paci, Ervin; Premti, Irakli; and Disha, Drilona, "A Synthesis of Architectural Form for Three Different Structural Systems" (2014). UBT International Conference. 11.

https://knowledgecenter.ubt-uni.net/conference/2014/all-events/11

This Event is brought to you for free and open access by the Publication and Journals at UBT Knowledge Center. It has been accepted for inclusion in UBT International Conference by an authorized administrator of UBT Knowledge Center. For more information, please contact knowledge.center@ubt-uni.net. 


\title{
A Synthesis of Architectural Form for Three Different Structural Systems
}

\author{
Hektor Cullufi ${ }^{1}$, Altin Bidaj ${ }^{2}$, Ervin Paci $^{3}$, Irakli Premti ${ }^{4}$, Drilona Disha ${ }^{5}$ \\ 12345 Polytechnic University of Tirana, Faculty of Civil Engineering, Tirana, Albania \\ ${ }^{4}$ Albanian University, Faculty of Architecture and Engineering, \\ Tirana, Albania
}

\begin{abstract}
Architectural form is often used but less frequently defined. Architectural form is an inclusive term that refers primarily to a building's external outline or shape, and to a lesser degree references its internal organization and unifying principles. Shape encompasses various visual and relational properties; namely size, color and texture, position, orientation and visual inertia. Form is therefore generally and primarily understood as the shape or three dimensional massing, but also encompasses additional architectural aspects including structural configuration and form, in so far as they may organize and unify an architectural design.
\end{abstract}

Keywords: structure, shell, design practice, form, catenary, fabric

\section{Introduction}

In this paper we consider three structural systems that typically exemplify a synthesis between architectural and structural form. In these cases structure defines architectural form and often functions, at least partially, as the building envelope. The order in which the structural systems are discussed begins with shell structures that of all structural systems most closely integrate the two forms. The two other remaining systems follow a progression from curved to more planar forms. [1], [2], [15].

\section{Shell, Fabric and Catenary Structures}

\subsection{Shell Structures}

In the wide range of building structures shell structures achieve the most pure synthesis of architectural and structural forms. Also known as 'surface structures', shells resist and transfer loads within their minimal thicknesses. They rely upon their three-dimensional curved geometry [3],[4],[5] and correct orientation and placement of supports for their adequate structural performance. When constructed from reinforced concrete, many shells, reveal smooth curved surfaces inside and out, much like those of a hen's egg [7]. Shells unify architectural and structural form as they spring from their foundations and continuously curve over to envelop interior space (Fig. 2.1). At the Palazzetto dello Sport, Rome, the shell surface does not meet the foundations directly but ends at the eaves level where inclined struts resist the outward thrusts (Fig. 2.2). This shell also defines the roof form, functioning simultaneously as structure and enclosure. Its interior surfaces are ribbed (Fig. 2.3). Interlacing ribs that evidence its precast concrete formwork segments both increase shell stability and achieve a much admired structural texture. [6] 


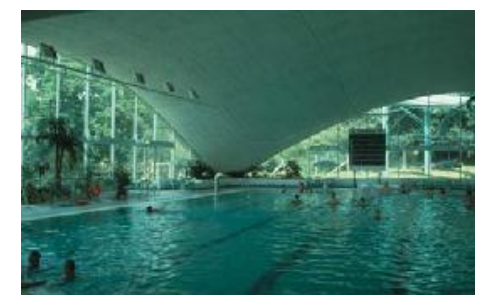

Fig. 2.1 Interior of a concrete shell structure.

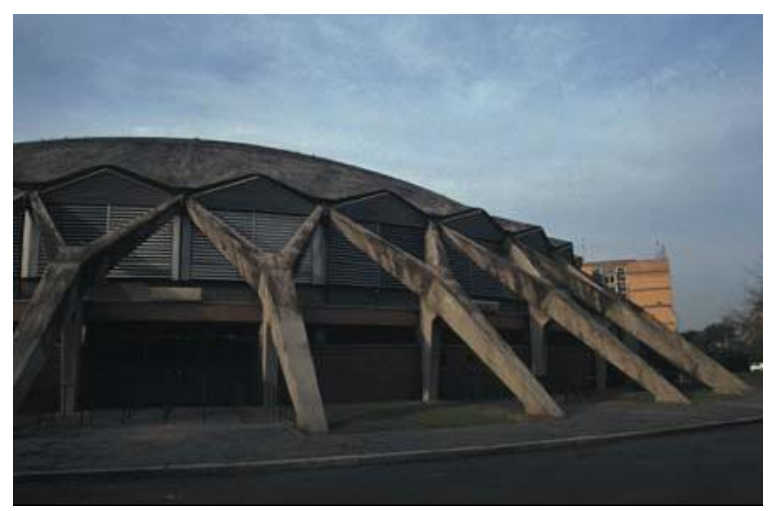

Fig. 2.2 Palazzetto dello Sport, Rome, Italy, Pier Luigi Nervi with A Vitellozzi, 1957

Shell structures can also be constructed from linear steel or timber members, as in the cases of geodesic or other braced domes. Although in these cases the many short structural members shape a faceted structural surface which must then be clad, structure nonetheless defines architectural form. The huge greenhouses of the Eden Project, Cornwall, are such examples (Fig. 2.4). Hexagons, a geometrical pattern found in many naturally occurring structures, are the building blocks of these shells, or biomes as they are called. Due to the long spans of up to $124 \mathrm{~m}$, the outer primary hexagonal steel structure is supplemented by a secondary inner layer of tension rods (Fig. 2.5). By increasing structural depths the diameters of the main hexagon tubes could be more than halved to less than $200 \mathrm{~mm}$, considerably improving their overall transparency. The biomes demonstrate the degree of synthesis of forms possible with shell structures. Although in this project structure acts as building skin in a very minor way, it defines an organic architectural form whilst achieving rational, economic and transparent construction.

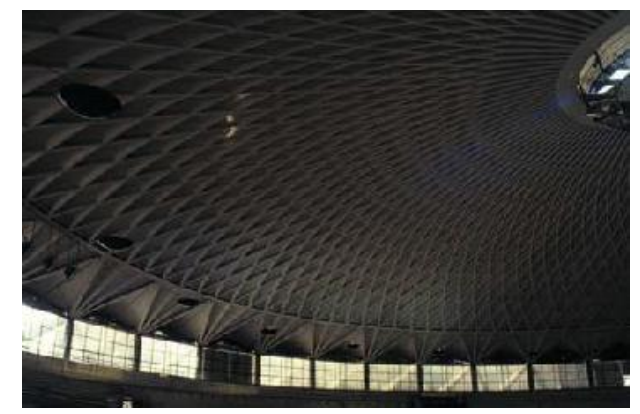

Fig. 2.3 Interior ribbed surface of the shell. 


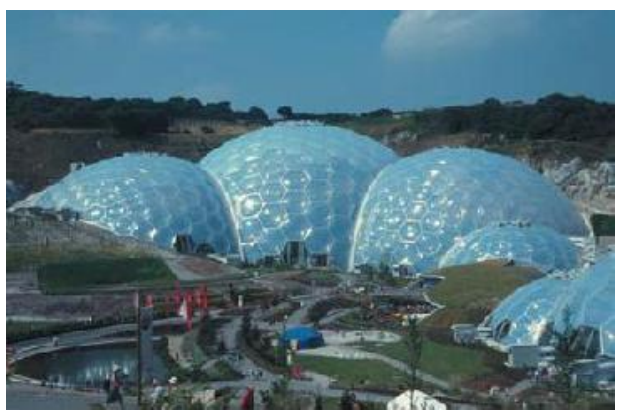

Fig. 2.4 Eden Project, Cornwall, England, Nicholas Grimshaw \& Partners, 2001. A cluster of interlinked biomes.

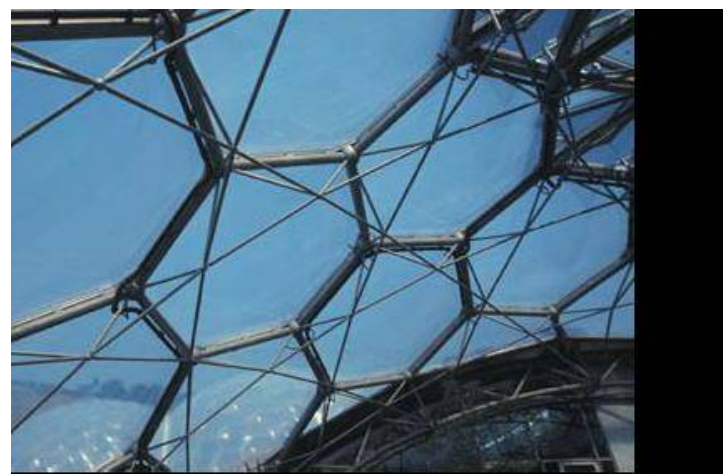

Fig. 2.5 Biome interior structure consisting of outer primary hexagons and an inner layer of braced rods.

\subsection{Fabric Structures}

Fabric or membrane structures represent another type of surface structure. These structures, where tensioned fabric initially resists self weight and other loads, also rely upon their three-dimensional curvatures for structural adequacy. Fabric form, thickness and strength must match the expected loads, and all surfaces must be stretched taut to prevent the fabric flapping during high winds [8], [9], [10]. Like shell structures, there is no distinction between the architectural and the structural forms. Fabric structures, however, require additional and separate compression members to create high-points over which the fabric can be stretched. Arches, with their curved forms, are well suited and aesthetically the most sympathetic to the curving fabric geometry, but masts, flying struts and cables which are more common, introduce dissimilar geometric forms and materiality. Their linearity, density and solidity contrast with the flowing double-curved, light-weight and translucent fabric surfaces, and can sometimes visually disturb the fabric's overall softness of form.

At the Stellingen Ice Skating Rink and Velodrome, Hamburg, four masts that project through the fabric and connect to it by tension cables provide the primary means of compression support (Fig. 2.6). Eight flying struts provide additional high points. From interior cables tensioned between the four outermost masts they thrust upward into the fabric to increase its curvature and improve its structural performance. The building interior illustrates clearly the different architectural qualities of the fabric and its linear supporting structure - masts, flying struts and interior steel cables (Fig. 2.7). 


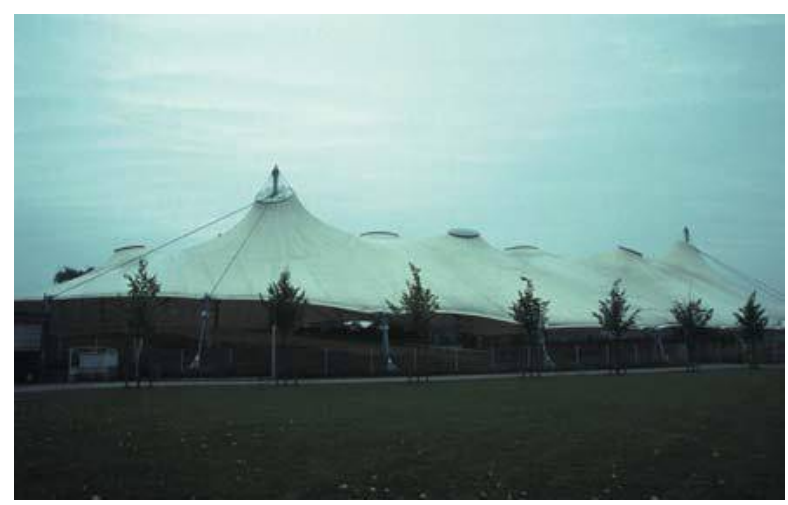

Fig. 2.6 Stellingen Ice Skating Rink and Velodrome, Hamburg, Germany, Silcher, Werner Partners, 1996. Overall form.

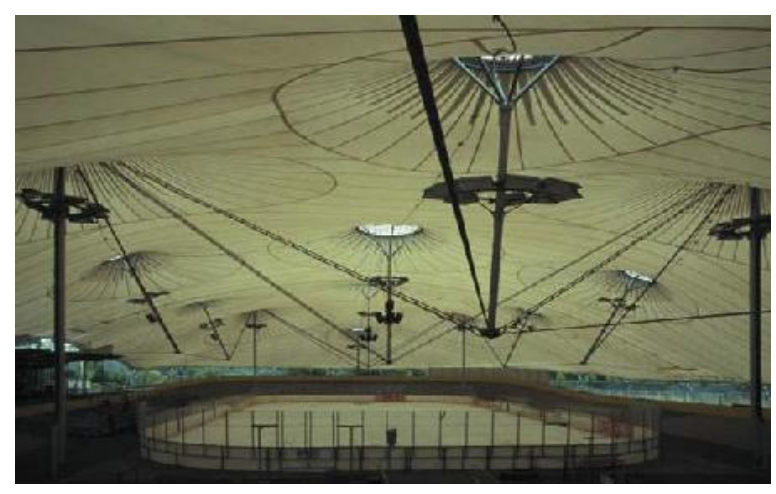

Fig. 2.7 Contrasting architectural qualities of fabric surface and interior structural elements.

\subsection{Catenary Structures}

Catenary structures, like fabric structures, transfer loads to their supports through tension. The simplest example of a catenary is a draped cable spanning between two high points. Catenaries that support roofs are usually designed so that the roof self-weight exceeds the wind suction or uplift pressures that would otherwise cause excessive vertical movement. Reinforced concrete is sometimes chosen as a catenary material for this reason. The concrete encases the tension steel protectively and provides the exterior and interior surfaces. Lighter catenary systems are possible provided that wind uplift is overcome with ballast or a separate tie-down system. Catenary tension members are usually distinct from the cladding and exposed within or outside the building envelope. The Portuguese Pavilion canopy, Lisbon, and Hall 26 of the Trade Fair, Hanover, illustrate these two approaches [13].

At the southern end of the Portuguese Pavilion, built for Expo '98, a ceremonial plaza $65 \mathrm{~m}$ long by 58 $\mathrm{m}$ wide is sheltered by a $200 \mathrm{~mm}$ thick reinforced concrete catenary slab. It has been variously described as a 'veil' or 'tent' on account of its remarkable slimness and draped form (Fig. 2.8). 


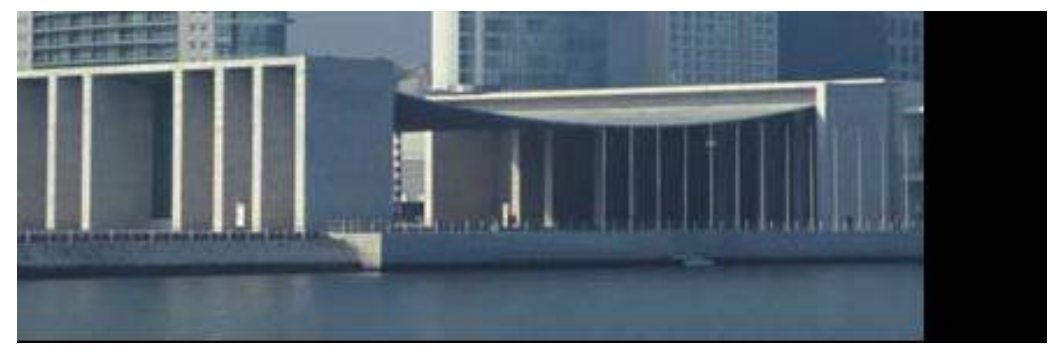

Fig. 2.8 Portuguese Pavilion, Lisbon, Portugal, Alvaro Siza, 1998.The canopy drapes between two porticoes.

Two porticoes, one at each end, act as massive end-blocks to resist the catenary tension. Within each portico, nine parallel walls or buttresses resist the large inwards pull from the hanging slab. Its simplicity of detailing carries through to the design of the porticoes which are not at all expressive of their important structural roles. Their simple orthogonality would have been compromised if the common procedure of tapering buttress walls in acknowledgement of the reduction of their bending moments with height had been undertaken [14]. The piers of the Dulles International Airport Terminal, Washington, DC, illustrate the usual approach. Their tapering as well as their inclination express the strain of supporting a heavy reinforced concrete roof [11], [12] (Fig. 2.9).

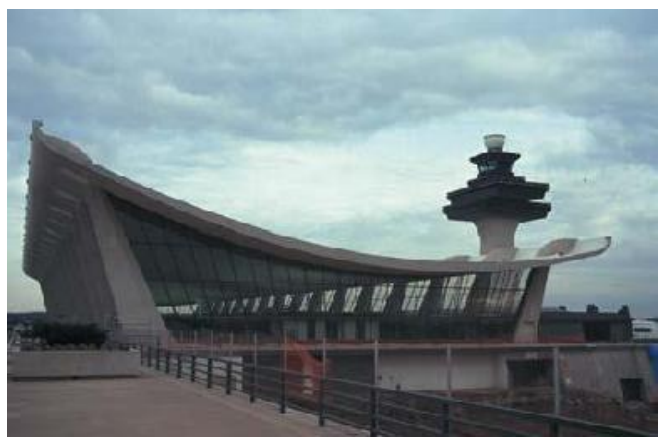

Fig. 2.9 Dulles International Airport, Washington, DC, USA,Saarinen (Eero) and Associates, 1962. Inclined piers support the catenary slab.

\section{Conclusions}

In order to discuss the relationships between architectural and structural form an understanding of the term architectural form is intentionally narrowly defined as the massing or the enveloping form. The reality of most architectural design practice is that structure rarely generates architectural form, but rather responds to it in a way that meets the programme and ideally is consistent with design concepts. Selected buildings illustrate three categories of relationship between architectural and structural form. No one category or attitude to the relationship between forms is inherently preferable to another. The examples provided merely hint at the breadth of potential similarity or diversity of forms that can lead to exemplary architecture.

\section{References}

1. Ching, F. D. (1996). Architecture: Form-Space and Order, 2nd edn. Van Nostrand Reinhold. Suckle, A. (1980). By Their Own Design. Whitney Library of Design. Quoted by Suckle (1980), p. 14.

2. Quoted in Collins, P. (1998). Changing Ideals in Modern Architecture 1750-1950, 2nd edn. McGill-Queen's University Press, p. 214. 
3. Nervi, P. L. (1955). Concrete and structural form. The Architect and Building News, 208 (27), pp. 523-9.

4. Glasser, D. E. (1979). Structural considerations. In J. Synder and A. Catanse (eds), Introduction to Architecture. McGraw-Hill, pp. 268-71.

5. For other examples see J. Chilton (2000). The Engineer's Contribution to Contemporary Architecture: Heinz Isler. RIBA Telford.

6. Thiel-Siling, S. (ed.) (1998). Icons of Architecture: the 20th Century. Prestel, p.

7. 125 .

8. Blundell-Jones, P. (2002). Modern Architecture Through Case-Studies. Architectural Press, p. 153.

9. Bussel, A. (2000). SOM evolutions: Recent Work of Skidmore, Owings \& Merrill.

10. Birkhäuser.

11. Quoted by Davey, P. (1996). In The boot and the lace maker. Architectural Review, 199 (3), p. 72.

12. Welsh, J. (1994). Willing and able. RIBA Journal, April, pp. 37-47. Moss, E.O. (2000). Eric Owen Moss: the Stealth. GA Document, 61, pp. 60-62.

13. Byard, P. S. (1998). The Architecture of Additions: Design and Regulation. Andrew Charleson (2005) Structure As Architecture, Elsevier 